\title{
The Green Management Practice by Local Government
}

\author{
Zikri Muhammad ${ }^{1,2}$, Jasmi Abu Talib ${ }^{1}$, Kamarul Md. Shah $^{1}$, Jaharudin Padli ${ }^{1}$, Bayu Taufiq Possumah ${ }^{1}$ \\ ${ }^{1}$ School of Social and Economic Development, Universiti Malaysia Terengganu \\ ${ }^{2}$ Institut Oseanografi dan Sekitaran, Universiti Malaysia Terengganu
}

\begin{abstract}
in developing countries face an unprecedented challenge to cut annual management budget without compromising the services quality. Local government top management has been pressured by politicians and public to cut costs but keep up high level quality services. Therefore this study has been analysed the use of green management practise among local government agencies to cut the annual budget and protect the environment. The online services are the main element for green management practise by local government for this study. This study interviewed 630 residents to test the online services provided by local government in Manjung, Perak. Out of the total samples, 92 percent respondents use the online services. Meanwhile, 90 percent of respondents are satisfied with the online services. More than 81 percent respondents agreed that online services can be a medium to share their local knowledge to the local government to cut budget and protect the environment. Besides that, the study also found that, the support by consumer and the internet speed have a significant relationship with the online services usage. This study suggested that, local government should increase the online services to reduce budget and protect the environment simultaneously.
\end{abstract}

\section{Introduction}

The Green Management Practices (GMP) is one of the sustainable environmental management. There are several issues of GMP such as policies, procedures, implementation and the public and the private sectors resistance. As we know the rapid urbanization has change the lifestyle of urban citizen, which is lead on the environment damage. To prevent the situation, not only individual, but all the parties including private sector and government agencies must take part to practise the sustainable development. Nowadays, most of developed and developing countries produce the strong policies and procedures on the environment. The GMP by government agencies will create the good image to organization and produce the improve service quality. The GMP by local government will ease the front line service to their customer especially local people. One of the GMP by local government is the use of online services to cut the cost and shorter time. The online services is one of the public infrastructures provided by local government to cut budget and time for high quality services. The public infrastructures provided by local government are the most importance factors that influence the residential satisfaction [1]. Besides that, the GMP through online service will improve the relationship between local government and their customers. Research by Smith show that 82 percent of internet users which represent 61 of all-American adults looked for information or completed a transaction on a government website [2]. Meanwhile, the study by Benton and Simon found that many councils in the USA have already transformed the way they give information and how they manage transactions through online [3]. Nowadays, most local authorities no longer rely solely on 'in-house' operations to deliver either public services or their own internal functions, they need to share their information with other parties' especially with local residents [4]. This can be done through online system where all parties can give information. So, this study will find the level of satisfaction on online services provided by local authority and the readiness of local people to use the online system for dissemination of local knowledge. 


\section{Methodology}

The unit of analysis in this study are the residents of Manjung and Kerian in Perak. This study interviewed 630 residents to test the online services provided by local government. Out of the total samples, 92 percent respondents use the online services. This study measured the satisfaction of online service by local government among the residents' area for urban and suburbs. The measurement covers the online services provided by local authority. The indicators in this study include:
1. E- Rental
2. E-Licensing
3. E-Complaints
4. E- Assessment
5. E- Payment
6. E- Compound (Car)
7. E- Compound (Other)

This measurement used seven-point Likert-type scale ranging from $1=$ Very dissatisfied to $7=$ Very satisfied for all the quality of online services performance items. This study also will explore the level of readiness of respondent to dissemination of local knowledge by using the online system provided by local authority. For this measurement, this study used five point likert-type scale ranging from 1. Strongly disagree to 5. Strongly agree. To develop comprehensive indicators of online services performance, this research measure total online services provided, level of online safety, method of payment, time consumption, the accuracy of online services and the mobile technology used. A set questionnaire has been developed to get response from customers about the level of satisfaction. The broad aims of the research was to explore the online services performance based on resident's perspective practice by local authority. This study basically used convenience sampling, but taking into account housing site and the different types of housing. This will make sure that the various subgroups in the population are represented. Out of 640 answered questionnaires replied and only 630 were usable. This is representing 98.4 percent of response rate. This study applied the descriptive analysis, factors analysis and correlation analysis to answer the research question and objective.

\section{Findings}

The majority of the respondents are male with 80.9 percent males and 19.1 percent females. With regard to age, most of the respondent's ages are 41 to 50 years old. In term of marital status, 90.6 percent of the married residents, 1.3 percent is single, and 8.1 percent is divorced. About 78.5 percent had education below or equal to college diploma level compared to other group of educations. The large majority respondents had an income of less than RM5000 per month (95.3 percent) compared to respondents with income more than RM5000 per month (4.7 percent). All the respondents are randomly selected to make sure the sampling bias did not happen.

Table 1: The mean level of satisfaction and Cronbach's alpha value.

\begin{tabular}{|c|c|c|c|}
\hline Indicators & Item & $\begin{array}{c}\text { Mean Level of } \\
\text { Satisfaction } \\
\end{array}$ & $\begin{array}{c}\text { Cronbach's } \\
\text { alpha }\end{array}$ \\
\hline \multirow{6}{*}{ E-Rental } & Total online services provided & \multirow{6}{*}{5.8} & \multirow{6}{*}{0.82} \\
\hline & Level of online safety & & \\
\hline & Method of payment & & \\
\hline & Time consumption & & \\
\hline & The accuracy of online services & & \\
\hline & Mobile technology & & \\
\hline E-Licensing & Total online services provided & 6.7 & 0.85 \\
\hline
\end{tabular}




\begin{tabular}{|c|c|c|c|}
\hline & Level of online safety & & \\
\hline & Method of payment & & \\
\hline & Time consumption & & \\
\hline & The accuracy of online services & & \\
\hline & Mobile technology & & \\
\hline \multirow{6}{*}{ E-Complaints } & Total online services provided & \multirow{6}{*}{6.0} & \multirow{6}{*}{0.78} \\
\hline & Level of online safety & & \\
\hline & Method of payment & & \\
\hline & Time consumption & & \\
\hline & The accuracy of online services & & \\
\hline & Mobile technology & & \\
\hline \multirow{6}{*}{ E-Assessment } & Total online services provided & \multirow{6}{*}{8.5} & \multirow{6}{*}{0.84} \\
\hline & Level of online safety & & \\
\hline & Method of payment & & \\
\hline & Time consumption & & \\
\hline & The accuracy of online services & & \\
\hline & Mobile technology & & \\
\hline \multirow{6}{*}{ E-Payment } & Total online services provided & \multirow{6}{*}{7.5} & \multirow{6}{*}{0.76} \\
\hline & Level of online safety & & \\
\hline & Method of payment & & \\
\hline & Time consumption & & \\
\hline & The accuracy of online services & & \\
\hline & Mobile technology & & \\
\hline \multirow{6}{*}{ E-Compound (Car) } & Total online services provided & \multirow{6}{*}{6.0} & \multirow{6}{*}{0.84} \\
\hline & Level of online safety & & \\
\hline & Method of payment & & \\
\hline & Time consumption & & \\
\hline & The accuracy of online services & & \\
\hline & Mobile technology & & \\
\hline \multirow{6}{*}{ E-Compound (Other) } & Total online services provided & \multirow{6}{*}{6.5} & \multirow{6}{*}{0.85} \\
\hline & Level of online safety & & \\
\hline & Method of payment & & \\
\hline & Time consumption & & \\
\hline & The accuracy of online services & & \\
\hline & Mobile technology & & \\
\hline
\end{tabular}

\section{Reliability Test}

According to Nunnally's alpha values equal to or greater than 0.70 can be considered a sufficient condition [5]. This study used Cronbach alpha value for testing the inter-item consistency. The result shows that all the online service by local authority have the Cronbach value more than 0.70 (0.76-0.85). This study concluded that these measures had sufficient reliability. 


\section{Level of Satisfaction}

Generally, this study found that 90 percent of respondents satisfied with the online services. Table 1 shows that mean for level of satisfaction in all indicators for online service more than 5.6. It shows that most of the respondent are satisfied for all online services. This can be concluded that local people are ready to use the technology for their convenient especially payment or complaint services. The use of technology especially online services is one of the GMP initiative by local authority to protect the environment. All the transaction can be done through online system. It will be reduced transportation cost, utility cost, and time-consuming. Besides that, this study also found that more than 81 percent respondents agreed that online services can be a medium to share their local knowledge to the local government to cut budget and protect the environment. They agreed that most of the local services especially for payment and communications' services can be done through online system. Out of 630 respondent 93 percent suggests that local authority should increase the online services for dissemination of local knowledge. Besides that, they can share the local knowledge to the local authority for local planning or land used planning. However, not all the services provided can be use as a channel for local people to sharing their local knowledge.

\section{Conclusion}

As a conclusion, GMP initiative by local authority by using the online services will protect the environment for sustainable future development. The use of technology can give many advantages not only GMP, it also can increase image and convenient for local people in term of transactions. Most of the local people will enjoy the services from their home or anywhere and at any time to transact with local authority. This GMP will create a good situation for all parties including local authority, local people, private sectors, or any other parties. In this scenario all parties indirectly support the local authority to carry out the GMP for sustainable development. This study also found that the use of technology also can be used for local knowledge dissemination for urban and land use planning.

\section{Acknowledgement}

This paper is part of the outcome for the Long-Term Research Grant Scheme (LRGS) program on "Conceptualizing Local Knowledge: A Study on Sustainable Values of Local Wisdom and Indigenous Sciences” Specifically project (203/PTS/6727003) on “innovative Local Knowledge Repository Support System”.

\section{References}

1. Zikri M, Katiman R. Yusliza M.Y. (2010) Residential Satisfaction with Housing in the Malaysia Context. The International Journal of Interdisciplinary Social Sciences. 5 (2) 379-396.

2. Smith A. (2010) Government Online: The internet gives citizens new paths to government services and information. Sources : $\quad$ http://www.pewinternet.org/files/oldedia/Files/Reports/2010/PIP_Government_Online_2010_with_topline.pdf downloaded on 19 July 2017A.

3. Benton M. and Simon J. (2016) A Digital Vision of Digital of Local Government in 2025. Public Service Transportation Network. March 2016.NESTA 2016.

4. Sandford M. (2016) Local government: alternative models of service delivery. Briefing Paper Number 05950, 20 May

Source:https://study.sagepub.com/sites/default/files/H\%20of $\% 20 \mathrm{C} \% 20$ library $\% 20$ on $\% 20$ ousourcing.pdf downloaded on 19 July 2017.

5. Nunnally J.C. (1978). Psychometric Theory. McGraw Hill: New York (1978). 